May 2019

\title{
Early Childhood Pre-Professionals' Experience in a Study Abroad Program to Finland: Evaluation of Professional Growth, and Personal and Cultural Gains
}

\author{
Bingbing Zhang \\ University of Central Florida, bingbing.zhang@ucf.edu \\ Judit Szente \\ University of Central Florida, Department of Education, Florida, judit.szente@ucf.edu \\ Judith Levin \\ University of Central Florida, judith.levin@ucf.edu
}

Follow this and additional works at: https://digitalcommons.georgiasouthern.edu/ij-sotl

\section{Recommended Citation}

Zhang, Bingbing; Szente, Judit; and Levin, Judith (2019) "Early Childhood Pre-Professionals' Experience in a Study Abroad Program to Finland: Evaluation of Professional Growth, and Personal and Cultural Gains," International Journal for the Scholarship of Teaching and Learning: Vol. 13: No. 2, Article 16.

Available at: https://doi.org/10.20429/ijsotl.2019.130216 


\title{
Early Childhood Pre-Professionals' Experience in a Study Abroad Program to Finland: Evaluation of Professional Growth, and Personal and Cultural Gains
}

\author{
Abstract \\ recommendations are provided for future studies.

\section{Keywords} \\ study abroad, pre-professionals, early childhood education

\section{Creative Commons License} \\ c) (†) $\ominus$
}

The present study explores the experiences of fifteen Early Childhood pre-professionals on a University lead short-term study abroad program to Finland. The purpose of the study was to investigate the impact of the 10-day-long experience on students' attitudes and perceptions particularly on their professional growth, personal, and cultural gains. Daily reflective journals entries and questionnaires were used to capture insights of the phenomena. Data were collected prior to, during, and after the program. This phenomenological study also employed audio taped interviews to provide summaries of their experiences in Finland. Horizontalization was used and three emerging themes were explained. Conclusions and

This work is licensed under a Creative Commons Attribution-Noncommercial-No Derivative Works 4.0 License. 


\title{
Early Childhood Pre-Professionals' Experience in a Study Abroad Program to Finland: Evaluation of Professional Growth, and Personal and Cultural Gains
}

\author{
Bingbing Zhang, Judit Szente \& Judith Levin \\ University of Central Florida
}

Received I8 May 2018;Accepted 5 March 2019

\begin{abstract}
The present study explores the experiences of fifteen Early Childhood pre-professionals on a University lead short-term study abroad program to Finland. The purpose of the study was to investigate the impact of the I0-day-long experience on students' attitudes and perceptions particularly on their professional growth, personal, and cultural gains. Daily reflective journals entries and questionnaires were used to capture insights of the phenomena. Data were collected prior to, during, and after the program. This phenomenological study also employed audio taped interviews to provide summaries of their experiences in Finland. Horizontalization was used and three emerging themes were explained. Conclusions and recommendations are provided for future studies.
\end{abstract}

In recent years, there has been an increased effort placed on providing university students with more opportunities for cultural exchanges (Smith \& Yang, 20I7). For example, study abroad programs have been viewed as providing life changing experiences for many who had gone through such long- or short-term programs (DeGraaf, Slagter, Larsen \& Ditta, 20I3). Study abroad is also believed to bridge the gap between theoretical learning in the classroom and real-life experiences, thus it is viewed to provide a better understanding and learning of various practices in the field.

Study abroad programs have been offered since the 1970s in various forms, including short-term study programs, student exchanges, teaching practicums, field experiences, immersion programs or brief placements and attachments (Kabilan, 20I3). Numerous studies indicate the benefits of such programs for participants including enhancing knowledge and skills, increasing intercultural development and communication, developing cultural sensitivity and self-confidence, and opportunities for language proficiency related to identity (Benson, Barkhuizen, Bodycott \& Brown, 2012; Brown, Vesely \& Dallman, 2016; Kabilan, 20I3; Marx \& Moss, 20II; Ruddock \& Turner, 2007; Young, Natrajan-Tyagi \& Platt, 2015). One of the major goals of study abroad trips is to impact the knowledge and professional gains of participants. During a semester-long study abroad program to London, for example, Marx and Moss (20l I) found that the immersion experience of the culture and the school accompanied by reflective practices on the culture and oneself enhanced participants' intercultural development. Further, DeGraaf et al. (20I3), found that long-term professional and personal impacts of a study abroad program were in three areas: increased employment and/or educational opportunities, increased knowledge related to discipline or major, and influence on career choice.

Qualitative methodologies such as case study (Conner \& Roberts, 2015; Marx \& Moss, 20lI), narrative (Benson et al., 20I2), and phenomenological studies (Young et al., 20I5) were commonly applied in the research of study abroad programs to explore students' perceptions, identity, and cultural competence and development. There are very few phenomenological studies to capture the holistic experience of study abroad programs due to the emphasis on journaling and questionnaires instead of interviews. Further, most of these previous studies focused on the cultural and personal aspects of the study abroad programs and less focus was placed on the individuals' professional enrichment
(McCartney \& Harris, 20 I4; Czerwionka,Artamonova \& Barbosa, 20I5). There are also very few studies that focus specifically on early childhood pre-service teachers' study-abroad experiences -especially on their professional understanding and their personal and cultural gains (e.g., McCartney \& Harris, 20I4; Vatalaro, Szente \& Levin, 20I5; Rahikainen \& Hakkarainen, 20I3).

Nordic countries' social welfare model provides universal services for families and the education and care of young children are shared between families and the public institutions (Pölkki \& Vornanen, 2016). The country of Finland is known for having the world's leading early childhood system, so it is an excellent site for a study abroad program for early childhood preservice teachers. Based on the above, the present study was undertaken with a group of preservice early childhood teachers during and after their Study Abroad Trip to Finland in Spring 2016 to explore their personal, professional, and cultural experiences.

\section{Research Questions}

The following Research Questions guided this study:

RQ I:What are the experiences of early childhood pre-professionals on a Study Abroad Program to Finland?

\section{RQ2: How may a Study Abroad Program af- fect participants' professional understanding?
RQ3: How may a Study Abroad Program af- fect participants' personal and cultural com- petence?}

\section{Overview of the Study Abroad Program to}

Finland

The program was offered by a public university in the southeastern region in the United States. This southeastern university provides a wide variety of study abroad programs including short-term programs, exchange programs, partner programs, and internship programs. This study was a 10-day program during Spring 2016 in two cities, Tampere and Helsinki. Participants explored the world-famous Finnish education system by visiting early childhood centers and elementary schools, experienced cultural events and historical sites, museums, and a national celebration, Vappu. Participants were also able to attend university 
lectures, a language course in Finnish, and participate in discussions with representatives of the National Board of Education.

\section{METHODOLOGY}

\section{Researchers' Role}

This phenomenological research study is set out to describe the lived experience of a phenomenon and the universal essence or the nature of the experience among several individuals (Creswell, 2013; Van Manen, 1990). Based on Moustakas (1994), the description of the phenomena consists of two parts: "what" and "how" of the lived experience for the participants. In phenomenological research, it is recommended that the researchers bracket their own experiences and biases to fully describe how participants view a phenomenon (Creswell, 20I3). In this study, a qualitative research expert conducted and tape-recorded the interviews, and the first author transcribed the tapes and analyzed the data.

\section{Sample}

This study used purposeful sampling strategy and adopted criterion sampling. The needed number of participants of qualitative phenomenological study varies but, as Polkinghorne (as cited in Creswell, 2013, p.149) suggested, it is acceptable to include "5 to 25 individuals who have all experienced the phenomenon." In this study, there were 15 participants who were all part of the research. All were female except one. Nine were white, four were Hispanic, one was Black, and one was Asian. The 15 participating students consisted of nine undergraduate-, five graduate-, and one post-doc- students. Of the 15 participants, thirteen were seeking Early Childhood degrees, one in education leadership, and one in mathematics education. Prior to the trip, 12 had some type of international travel experiences and five of them had been on study abroad programs. All participants were responsible for their program costs, travel and course credit.

\section{Instruments}

\section{Demographic Questionnaire}

This questionnaire was completed by all participants one month prior to the departure. It contained questions regarding the participants' gender, race, educational level, language skills, professional position, prior diversity experiences, and number of prior study abroad trips.

\section{Pre-Departure and Post-Trip Questionnaires}

The Pre-Departure Questionnaire was also completed one month prior to departure. It was intended to collect written reflective information about the participants' thoughts, insights and perceptions regarding the trip, the Finnish educational system, and the Finnish culture. The Post-Trip Questionnaire was completed one week after returning to the United States. Participants had two weeks to complete these and return them.

\section{Daily Reflective Journal Entries}

During the program, all participants completed Daily Reflective Journal Entries based on their daily observations, highlights and other thoughts about the program. Based on Husserl (1970) and Moustakas (1994), the journal entries were designed to collect facts of participants' natural attitude of their experience and perception. The following questions were included in the daily reflective journal entries: (I) What did you observe that affected you the most today?; (2) Tell me two things you learned today; and (3) Other thoughts you may want to share.The first author distributed the daily reflective journal pages in the morning and collected them the next day. There were a total of II daily entries per participant. All participants completed at least three quarters of their journal entries. All journal entries were typed up for further analysis.

\section{Interviews}

Five months after the end of the program, all participants received individual invitations to participate in a 30-45-minute semi-structured individual interview. The interview included open-ended questions to inquire about the phenomenon and gather participants' views about the program and their experiences. The face-to-face interviews were conducted in a conference room of the Education Building of the southeastern University campus. All interviews were tape-recorded with the permission of participants. Three participants volunteered for the interview.

These participants included a current Master of Science in Early Childhood Development and Education student, a current Ph.D. student in the Education Ph.D. Early Childhood Track, and an Early Childhood Post-Doctoral Student. All of these participants had rich experience as early childhood educators and prior study abroad experiences.

\section{DATA COLLECTION}

A consent was given to all participants informing them about the purpose of the research and the procedures. As indicated above, all 15 participants were given two questionnaires one month prior to departure, daily reflective journal entries on highlights of the day, and a post-trip reflective questionnaire. Three participants also volunteered to be interviewed five months after returning to the United States.

These data collection methods aligned with the requirements of a transcendental phenomenological study that gathers data from various forms of documentations such as pre- and post-questionnaires, reflective daily journal entries, and reflective in-depth interviews. All instruments that were given to the participants were created and approved by two professors that were experienced in qualitative research. Participants were given a code that was indicated on all journal entries, questionnaires and forms and all responses were kept confidential and secure. Interview recordings were transcribed by the first author and transcripts and tapes were stored in a locked computer.

\section{DATA ANALYSIS}

Horizontalization was applied by going through the journal entries and interview transcriptions. This technique generated highlights, "significant statements," quotes, and sentences to understand how the participants understood the phenomenon (Creswell, 2013). The researchers also developed textual descriptions based on the participants' experiences in Finland. The next phase was structural description, in which the researchers wrote descriptions of the context or setting based on what the participants experienced about the phenomenon (Creswell, 2013). With the textual and structural description of the participants' experience, the researchers presented the combined descriptions to reveal the overall essence of the experience of the phenomenon. The researchers made meanings of the experience with quotes from the participants. To ensure the representation of data collected, In Vivo coding was used in the first cycle 
and Holistic Coding was used in the second cycle to generate themes.

\section{RESULTS}

Data analysis resulted in two main themes that were aligned with the research questions. These were: I) Professional Growth, and 2) Cultural and Personal Gains.

\section{Professional Growth}

Based on the field notes and transcripts of the interviews, the most often mentioned statement focused on how meaningful the school visits were and how much these United States students learned about the differences between various educational systems, policies, and infrastructures. Phrases such as "I learned a lot," "a great experience," and "awesome" were used often when describing the learning experiences during the day. The most important component of the trip was actually visiting early childhood and elementary school settings and reflecting on various educational practices. Students compared and contrasted the United States education system with the Finnish system on a daily basis.

The majority context emphasized areas such as a) teacher-child relationship, b) facilities/setting, and c) educational differences. The relationship between teachers and students was described as having freedom and independence. Stated points across the journals were "they [children] have freedom and [are] independent," "so much freedom," "Freedom and the children are trusted." Some participants also gave more in-depth details in the interview, for example,

The teachers have this trust for children that, you know, they trust that they [children] are going to do the right thing and they are ready to learn; and so what I saw is ... small groups of children playing in the room by themselves without, not even being constantly watched by a teacher; maybe not being checked on by the teacher for 5-10 minutes at a time. They were just trusted; the children are trusted in those rooms and it worked.

A lot of participants described the importance of play as they observed it in and outside of the schools. Each school that the participants visited had big playgrounds and there was very little teacher supervision or direction during free play. Children were given opportunities for free play in every 45 minutes and they were trusted by the adults to play without getting into trouble.

The school settings/facilities were viewed as beneficial and meaningful for children's learning and their social development. The classroom setup was stated as "minimalist" or "empty" compared to "over decorated" classrooms in the United States. There were also open hallways between classrooms, so the children could walk around freely. One student stated:

The classrooms had few 'things' or extra toys. The children were content and engaged. The children can go from room to room at any time and do whatever they want even with no supervision.

In terms of educational differences, the main observation that preservice teachers made during this trip was that Finnish teachers were trusted to teach so they had the freedom to alter their teaching based on children's individual needs. There was a shared vision for education throughout the system from preschools to the university level. Participants also highlighted two major differences between the United States and Finnish early childhood systems. One was that young Finnish children were not administered tests and evaluations in preschool and kindergarten--which is a common practice in the United States. The other observation was related to gifted children. The study abroad program participants did not observe any gifted classes or schools. Some of the participants' comments were:

Although we learned about gifted education in Finland, I really learned that my definition of gifted education is pretty narrow. Hearing the speaker so passionate about gifted education, I want to change my own practices.... Teachers in Finland want gifted students in a regular classroom, because gifted students can stimulate the learning of others by allowing them to assist their classmates.

Interviews revealed that a few months after their return, some of the students started to find a way to apply what they were observing in Finland to their work in the schools within the United States. One of the students shared:

So there are some really simple things I am thinking about, like bringing in 15 minutes of moving after a 45 minute instruction. It is something that is so easy, that can happen without passing any laws or doing anything. ... That is really backed by research that is really beneficial for children.

Another student described an urgent need to change United States practices in the field of early childhood:

It's kind of funny I still do comparisons, because I look at my children at the school that I teach; and I think about how it's almost making me more passionate to advocate for their developmental needs, because I saw the results of how there weren't any behavior issues.

She continued that United States teachers sometimes are fearful of doing what's right such as giving children recess every 45 minutes and allowing them to explore freely versus obeying the orders (such as test preparations) for their job would be at stake. She added "I am not saying we need to be Finland but we definitely need to make adjustments and look at the needs of our children's development, before we push push push..."

\section{Cultural and Personal Gains}

The majority of content in this area focused on I) increased cultural awareness; 2) increased foreign linguistic skills, and 3) increased personal understanding.

Students considered study abroad programs as great vehicles for increasing their cultural understanding and becoming more culturally sensitive which are viewed especially important for teachers with English Language Learners in their classrooms. Participants enjoyed cultural experiences such as visiting museums, and learning about Finnish history, languages, and values. Smiling faces were often drawn on the daily journals with statements such as "I LOVE FINLAND." The organized whole-group activities and local tours throughout the cities of Tampere and Helsinki were some of the cultural highlights for the participants. One student commented:

I learned a lot about Finland's history... The history ... is amazing. The Finnish, Swedish, and Russian influence is extremely evident. 
During a major national celebration in Helsinki, study abroad participants mingled with locals and learned about other Finnish traditions. The majority of the participants expressed their excitement in participating in the event: "I went to the big park... celebrating May It ... Everyone was surprisingly calm considering it was a 'party'."

Students also pointed out the culture of safety. One of the participants mentioned that she felt safer in Finland than in the United States:

I never had concerns about my safety [in Finland]. I felt comfortable to walk outside of the hotel by myself and it never occurred to me to worry. ... I am very aware of my surroundings.... am here [in the US] walking to my car after work, I am like I need to worry about my safety. I always have it on the back of my mind but there wasn't a time I thought I needed to hold my money close to me or any of that.

In terms of increased linguistic skills, most participants were comfortable with being in a new linguistic environment. The importance of language as a part of culture was mentioned a few times. One of the students commented:

Finland is actually very interesting because pretty much everyone I encountered spoke English, and I learned that their word for hello is hei.... if you walked to up to somebody or to a restaurant or store and said "hi" or "hello", they would automatically speak to you in English.

This participant continued: "I think that [observing in the classrooms] was very interesting. ... watching the instructor in the classroom even though I didn't speak the language, and [observing] lot of teacher behavior and child behavior [that] was sort of universal."

Another student mentioned that although the presenter at one of the local universities did not have good English the effort was certainly appreciated:

I think Americans are like when you are in my country you are supposed to speak my language. It's sort of eye opening to travel to another country and see myself and other young adults. I expect you to speak to me in English even though I am in your country. So, I really did appreciate people whose English wasn't strong.

There were few students, however, who had difficulties with understanding the accents and communications. One student stated:"I cannot understand the presenter." "Finnish people have a hard time understanding things in English." "I really want to learn the language so I can submerge myself in the culture."

Regarding increased personal understanding, there was an interesting theme appearing in students' journals and during the interviews. Participants seemed to have pre-conceived values of Finland such as that the Finns were introverted, reserved, and seemed to keep a distance between them and other people. Many participants compared their own personal characteristics to those of the Finnish people.

One of the participants mentioned:

If we were in a group I would typically engage in conversation, but I am really not the type of person to start a conversation with a stranger, whether here in United States or in another country. I really didn't do a lot of that.
However, among her interactions with the study abroad group she discovered her needs to have high-level conversations with adults, versus just "shallow" conversation with her peer groups.

I think for me sometimes I don't get a lot of that [high-level conversations] with my peer group, so sometimes the conversation can be a little bit more shallow. So I surround myself with people [program leaders] who are intelligent, and they are mature and they like to have open conversations and talk about diverse things.... Sometimes that's just cool... I don't really get that a lot with my peer group.

\section{CONCLUSION}

Fifteen pre-service students from a university-led study abroad program were assessed in order to study the impact of their experiences in Finland. Assessments included reflective daily journal entries, pre- and post-trip questionnaires, and follow up interviews. The reflections included information about the impact of classroom observations, discussions with national educational leaders and early childhood professionals, and cultural experiences.

Two main themes resulted based on the data analysis which were I) Professional Growth, and 2) Cultural and Personal Gains. From the beginning, school visits appeared to be the most important aspect of the participants' experiences. Every participant talked about the school visits and how these schools compared to what participants had experienced in the United States. Among the main sub-themes, trust in children and teachers stood out in both the journal entries and the interviews. Participants reported that they could feel that the Finnish teachers trusted students to take responsibility for their learning, behavior, and classroom activities. This trusting relationship between the children and the teachers in the Finnish education system amazed, surprised and even at times shocked the participants.

The findings of the current study fit with those of McGillivray (2009) suggesting that international experiences provide early childhood teachers with the opportunity to explore the perceptions of their own field of study and diverse classrooms in unique ways. The findings also support those of Malewski et al. (20I2) and Patterson (20I5) regarding the impact of experiential learning, cultural, and knowledge gains of pre-service teachers during study abroad programs.

As expected, the study suggests that every participant brought their pre-existing experiences, values, and attitudes into the description of their experiences of this study abroad program. Not only did participants develop increased self-awareness and cultural perspectives (DeGraaf et al., 20I3; McCartney, \& Harris, 20I4; Vatalaro et al., 20I5), but they also developed a broader global vision that would most likely impact and/or transform their career goals (Brindley, Quinn, \& Morton, 2009).

Following the study abroad trip to Finland, the participants expressed passion to continue work to advocate for children in the United States which supported the benefits articulated by prior research (Trilokekar, \& Kukar, 20I I; Vatalaro et al., 2015). The participants shared how this study abroad trip also enhanced their interpersonal skills and developed a stronger relationship with the professors who led the trip.The program also provided a unique experience for the participants to increase their global competence and self-confidence especially for those 
who embraced the new experience of independent travel and exploration in a foreign country. Participants reflected on their personal beliefs and weighed many of them based on conversations with locals, and what they experienced from new foods, educational system, and government operations.

In conclusion, the findings from the Early Childhood Finland Study Abroad program supports the notions of professional, personal and cultural gains of the participants. The new hands-on international experiences, ideas, different observed educational and cultural values, personal growth and understanding they indicated, will certainly benefit their future coursework and can also be applied to their future career with young children, thus making them more knowledgeable and culturally sensitive early childhood professional. Additionally, this experience left participants wanting to experience diverse cultures and educational settings even more.

\section{RECOMMENDATIONS}

Based on the present research, the following future studies are recommended. Future investigation can add an observation component prior to leaving for the study abroad program that may capture the behavior, verbal cues and group interactions in order to be able to compare those with the post trip data. Researchers could also document debriefing meetings during the trip to capture the spontaneous reflective questions, thoughts and memos in order to present a better picture of the specific reflective experiences during the trip. Researchers may also interview the participants before the trip to examine their perceived experiences, so they could be compared to post trip interview data.

\section{REFERENCES}

Benson, P., Barkhuizen, G., Bodycott, P., \& Brown, J. (20I2). Study abroad and the development of second language identities. Applied Linguistics Review, 3(1), 173-193. doi:I0.15I5/applirev-20I 2-0008

Brindley, R., Quinn, S., \& Morton, M. L. (2009). Consonance and dissonance in a study abroad program as a catalyst for professional development of pre-service teachers. Teaching and Teacher Education: An International Journal of Research and Studies, 25(3), 525-532. doi:I0.1016/j.tate.2008.09.012

Brown, E. L., Vesely, C. K., \& Dallman, L. (2016). Unpacking biases: Developing cultural humility in early childhood and elementary teacher candidates. The Teacher Educators' Journal, 9, 7596.

Conner, N. N., \& Roberts, T. G. (2015). The cultural adaptation process during a short-term study abroad experience in Swaziland. Journal of Agricultural Education, 56(I), I55-17I. doi:10.5032/jae.2015.01 I55

Creswell, J.W. (20I3). Qualitative inquiry and research design: Choosing among five approaches. Los Angeles, CA: Sage.

Czerwionka, L.,Artamonova,T., \& Barbosa, M. (20I5). Intercultural knowledge development: Evidence from student interviews during short-term study abroad. International Journal of Intercultural Relations, 49, 80-99. doi: I0.1016/j.ijintrel.2015.06.012

DeGraaf, D., Slagter, C., Larsen, K., \& Ditta, E. (2013). The longterm personal and professional impacts of participating in a study abroad program. Frontiers:The Interdisciplinary Journal of Study Abroad, 23, 42-59.

Husserl, E. (1970). Logical investigations (Vols. I \& 2) (J. N. Findlay, Trans.). New York: Humanities Press.
Kabilan, M. K. (20I3). A phenomenological study of an international teaching practicum: Pre-service teachers' experiences of professional development. Teaching and Teacher Education, 36, 198-209. doi:10.1016/j.tate.2013.07.013

Malewski, E., Sharma, S., \& Phillion, J. (20I2). How international field experiences promote cross-cultural awareness in preservice teachers through experiential learning: Findings from a six-year collective case study. Teachers College Record, I / 4(8), I-44.

Marx, H., \& Moss, D. M. (20I I). Please mind the culture gap: Intercultural development during a teacher education study abroad program. Journal of Teacher Education, 62(I), 35-47.

McCartney, H., \& Harris, T. (20I4). The image of the child constructed and transformed by preservice teachers in International contexts. Action in Teacher Education, 36(4), 264-282.

McGillivray, G. (2009). Constructs of childhood: Enduring or open to change? Early years students' reflections on first hand experiences of childhood and early years education in a different country and culture. European Early Childhood Education Research Journal, I7(3), 27I-282. doi: I0.1080/I3502930903/0I 289

Moustakas, C. (1994). Phenomenological research methods. Thousand Oaks, CA: Sage.

Patterson, T. (20I5). The transformative power of travel? Four social studies teachers reflect on their International professional development. Theory and Research in Social Education, 43(3), 345-37I.

Pölkki, P. L., \& Vornanen, R. H. (20I6). Role and success of Finnish early childhood education and care in supporting child welfare clients: Perspectives from parents and professionals. Early Childhood Education Journal, 44(6), 58I- 594. doi:I0.1007/ s I0643-0I5-0746-x

Rahikainen, K., \& Hakkarainen, K. (20I3). Nordic experiences: Participants' expectations and experiences of short-term study abroad programs. Scandinavian Journal of Educational Research, 57(5), 467-487. doi:10.1080/003।383।.20I2.6687 06

Ruddock, H., \& Turner, D. (2007). Developing cultural sensitivity: Nursing students' experiences of a study abroad programme. Journal of Advanced Nursing, 59(4), 36I-369. doi: I 0. I I I I/j. I 365-2648.2007.043 | 2.x

Smith, B. P., \& Yang,W. (2017). Learning outcomes in an interdisciplinary study abroad program: Developing a global perspective. Journal of Family and Consumer Sciences, 109(1), 43-50.

Trilokekar, R. D., \& Kukar, P. (20II). Disorienting experiences during study abroad: Reflections of pre-service teacher candidates. Teaching and Teacher Education, 27(7). I I 4 I- I I 50. doi: I0.10I6/j.tate.20II.06.002

Van Manen, M. (1990). Researching lived experience: human science for an action sensitive pedagogy. London:Althouse Press.

Vatalaro, A., Szente, J., \& Levin, J. (20I5). Transformative learning of pre-service teachers during study abroad in Reggio Emilia, Italy: A case study. Journal of the Scholarship of Teaching and Learning, I 5(2), 42-55.

Young, J.T., Natrajan-Tyagi, R., \& Platt, J. J. (2015). Identity in flux: Negotiating identity while studying abroad. Journal of Experiential Education, 38(2), |75-I88. 